\title{
THE BURDEN OF KNOWLEDGE MANAGEMENT IN THE INFORMATION AGE: A THEORETICAL APPROACH TO MITIGATING LOST KNOWLEDGE
}

\author{
Benjamin Aaron Stahl, Robert Morris University, basst49@mail.rmu.edu \\ Brian Buckles, Robert Morris University, bkbst119@mail.rmu.edu
}

"Knowledge management within firms is the heart of succession planning" (Stovel \& Bontis, 2002, p. 309)

\begin{abstract}
The authors propose that there are two critical issues currently facing organizations that must be addressed as part of any knowledge management plan; an aging workforce, and the rise of the knowledge worker in the information economy. Accordingly, as organizations stand to lose knowledge due to a generation entering retirement; they are also at the mercy of the knowledge worker. A question that all organizations must ask themselves is: how do we mitigate the loss of intellectual capital during the process of transferring inter-organizational knowledge? A functional description of knowledge and knowledge management is provided to frame the importance of knowledge management to an organization's sustainability and longevity. The authors then offer an enhanced version of their theoretical knowledge transfer process known as Replicative Indwelling. The two elements of this process, Replicative SPECTRUM and Accelerated Experiential Exposure, are offered as a means to assist organizations in the effective cross-generational transfer of knowledge while overcoming traditional barriers to knowledge management
\end{abstract}

Keywords: Knowledge Management, Knowledge Loss Mitigation, Cross-Generational Knowledge Transfer, Accelerated Experiential Exposure, Replicative Indwelling

\section{INTRODUCTION}

Whether implementing a new knowledge management plan or administering an existing one, there are two critical issues that must be addressed: an aging workforce (DeLong, 2004) and the rise of the knowledge worker (Drucker, 1993). This paper provides a theoretical and practical approach to address these two issues. First, a functional description of knowledge, knowledge management, and knowledge management barriers is provided to frame the importance of knowledge management to organizational sustainability and longevity. The authors then provide insight on the issue of both an aging workforce and a more mobile, younger workforce in an information-based economy. Lastly, the authors present an enhanced and revised theoretical knowledge transfer process known as Replicative Indwelling (Stahl \& Buckles, 2016). The two main components of Replicative Indwelling, the Replicative SPECTRUM and Accelerated Experiential Exposure, are presented to assist organizations in the effective cross-generational transfer of knowledge, the mitigation of lost knowledge, and the overcoming of knowledge management barriers.

\section{Knowledge}

The term knowledge has been defined in a number of ways (Berger \& Luckmann, 1966; Nonaka \& Takeuchi, 1995; Polanyi, 1962). The definition of knowledge that lends itself best to the discipline of Knowledge Management (KM) is that of Davenport and Prusak's (2000), which will serve as an operative definition. They define knowledge as:

...a fluid mix of framed experiences, values, contextual information, and expert insight that provides a framework for evaluation and incorporating new experiences and information. It originates and is applied in the minds of knowers. In organizations, it often becomes embedded not only in documents or repositories but also in organizational routines, processes, practices, and norms (p. 5). 
The importance of knowledge to the Information Economy can also be seen in Drucker's statement, that it "is the only meaningful resource today" (1993, p. 42). An effective knowledge management plan increases an

organization's effective utilization of knowledge, which in turn spurs innovation that positively impacts the organization's bottom line. For instance, the global oilfield services company Schlumberger saved \$75 million in the first year following the implementation of their knowledge management initiative (Albers, 2009). Stovel and Bontis (2002) indicate that from the opposite perspective, Fortune 500 companies spent nearly $\$ 12$ billion in 2000 on "duplicated work" (p. 309). They state that if knowledge and information were better managed, "the amount of money and time that could be saved is astounding" (p. 309). As attractive as this may sound, Stovel and Bontis (2002) cite a report from the Institute for Intellectual Capital Research (IICR) that only 5 percent of Canadian businesses have an established plan to deal with succession and employee turnover.

The essential elements of Davenport and Prusak's (2000) definition of knowledge entail "experience" and "expert insight" for it is the expert insight gained through experience that we seek to transmit from one generation to the next. As can be seen by the results of Stovel and Bontis' (2002) research, few organizations are implementing means to capture and transmit this knowledge; in essence, organizations lack a KM plan.

\section{Knowledge Management and KM Barriers}

Knowledge management plans are used to store, transfer, and manage knowledge in order to minimize the risk of lost intellectual capital (Liebowitz, 1999). Organizations thrive by analyzing facts in order to make decisions within a given context to optimize the likelihood of positive outcomes. The organization that is able to do this effectively, and retain this knowledge longitudinally, will have a greater likelihood of success than those who do not. Knowledge Management is defined as a:

focus...on knowledge processes - knowledge creation, acquisition, refinement, storage, transfer, sharing and utilization. These processes support organizational processes involving innovation, individual learning, collective learning and collaborative decision making (King, 2009, p. 11).

Organizations are faced with a number of internal and external challenges that affects their ability to successfully implement an effective knowledge management plan. As a result, prior to undertaking any knowledge management initiative, organizations must "be aware of common pitfalls and success factors that have been established from the experience of others" (Albers, 2009, p.8). Singh and Kant (2008) identified the nine most common barriers organizations are faced with when attempting to implement a knowledge management plan (See Figure 1).

Figure 1. Knowledge Management Barriers (Singh \& Kant, 2008, p. 142)

\begin{tabular}{|l|l|}
\hline Barrier & \multicolumn{1}{|c|}{ Barrier Description } \\
\hline 1. & Lack of top management commitment \\
\hline $\mathbf{2 .}$ & Lack of technological infrastructure \\
\hline $\mathbf{3 .}$ & Lack of methodology \\
\hline $\mathbf{4 .}$ & Lack of organizational structure \\
\hline $\mathbf{5 .}$ & Lack of organizational culture \\
\hline $\mathbf{6 .}$ & Lack of motivation and reward \\
\hline $\mathbf{7 .}$ & Staff retirement \\
\hline $\mathbf{8 .}$ & Lack of ownership of problem \\
\hline $\mathbf{9 .}$ & Staff defection \\
\hline
\end{tabular}

In order for an organization to stay relevant and informed they must implement an effective knowledge management plan. While there is no one size fits all knowledge management plan, organizations generally seek to find a knowledge management plan that has "practical, easy to follow steps that are built on best practices, pitfalls, and successes of companies that have gone before them (Albers, 2009, p. 9). As such, the authors believe that through the inclusion of Replicative Indwelling concepts to a broader KM plan, organizations can overcome at least four of the barriers identified by Singh and Kant (2008). 


\section{Issues in Information Systems \\ Volume 17, Issue IV, pp. 70-81, 2016}

\section{The Rise of the Knowledge Worker}

Knowledge is the only resource that matters. However, in order "[t]o accomplish anything this knowledge has to be highly specialized" (Drucker, 1993, p. 42). Drucker (2001) also states that "[i]nformation is data endowed with relevance and purpose. Converting data into information thus requires knowledge. And knowledge, by definition, is specialized" (p. 46). As knowledge workers continue to become more specialized, as sub-disciplines emerge from sub-disciplines, we increase our magnification and our focus, and as the degree of specialization increases, "[k]nowledge is now being applied to knowledge" (Drucker, 1993, p. 38). Malone, Laubacher, and Johns (2011) refer to this as "hyperspecialization." The field of Knowledge Management is an example of such a specialization. Specialists are, as Polanyi (1966) says, 'focusing on the particulars'.

The increasing degree of specialization that is necessary for organizations to continue to progress has changed the way that we understand knowledge. Drucker (1993) states that "[t]he change in the meaning of knowledge that began 250 years ago has transformed society and economy. Formal knowledge is seen as both the key personal resource and the key economic resource" (p. 38). Just as the Industrial Revolution relied on tangible resources, organizations in the Information Economy rely on knowledge in order to maintain their competitive advantage, and to increase and sustain their share of the market.

The proliferation of the knowledge worker is described by Hoffman, Casnocha, and Yeh (2013):

For most of the $20^{\text {th }}$ Century, the compact between employers and employees in the developed world was all about stability. Jobs at big corporations were secure: As long as the company did OK financially and the employee did his or her job, that job wouldn't go away. And in the white-collar world, careers progressed along an escalator of sorts, offering predictable advancement to employees who followed the rules... Then came Globalization and the Information Age (pp.49-50).

The rise of the Information Economy has changed the relationships between individuals and the organizations that they work for. The traditional 'corporate ladder' once used during an individual's career is no more, as knowledge workers typically spend 2-3 years at an organization prior to moving on to another (Hoffman, Casnocha, \& Yeh, 2013). Malone et al. (2011) enumerate numerous benefits and detriments of this seemingly transient workforce to the organization. However, this lack of organizational continuity and permanence of personnel presents significant challenges in regards to the implementation of an effective organizational knowledge management plan.

As can be seen, the problem now includes that of a retiring work force and the dynamics of a more mobile, younger work force. This creates a knowledge transfer paradox in which capturing and transferring an aging worker's knowledge becomes essential to organizational continuity and success, yet transferring "too much" knowledge to a more migratory, younger generation risks the compromise of organizational core proprietary knowledge. The authors submit that applying the Replicative Indwelling concepts can aid in identifying these critical elements of knowledge transference.

\section{Cross-generational Knowledge Loss}

DeLong (2004) addresses an issue which organizations across all sectors are currently faced; an aging workforce headed into retirement. This aging workforce presents a serious threat to the stability and continuity of an organization as that workforce takes with it into retirement years of knowledge gained by years of experience. What "...we now mean by knowledge is information in action." (Drucker, 1993, p. 42). Leonard and Swap (2004) suggest that it could take an individual up to 10 years to develop the in-depth knowledge that a highly skilled worker takes with them into retirement. Cross-generational knowledge loss is echoed by Liebowitz, Ayyavoo, Nguyen, Carran, and Simien (2007) who state that "[t]he demographics in the USA show that many organizations, especially the government, will face human capital challenges as the baby boomers are nearing retirement age" (p. 1133). The knowledge that this workforce has is of immense value to the organization; as in the information economy knowledge is the only resource that matters. 
While DeLong (2004) presents knowledge retention initiatives, and Liebowitz et al. (2007) analyze within-team cross-generational knowledge flows, this paper asserts that the transfer of tacit knowledge from one workforce generation to the next is critical to successful retention and utilization of knowledge by the organization. Organizations that have effective knowledge management programs are considered learning organizations (Farashahian \& Abbasi, 2011). It should be noted that "[k]nowledge management does not substitute for individual learning capacity. Our systems must augment the human capacity to learn, not seek to replace human thinking with rules and procedures" (Rogers \& Ryschkewitsch, 2009, p.4). In order to fully understand the knowledge they are receiving, a seeker must understand the context in which the knowledge was created. Rogers and Ryschkewitsch (2009) provide the following example:

a colleague may suggest a lesson from another mission he's heard about. The seeker may look up the lesson and find out who the system engineer was and call them to discuss a design question or risk element. In this way the systems all work in an integrated fashion in practice within the daily flow of work (p. 5, cited with permission from the author).

Leonard and Swap (2004) illuminate the relationship between experience and knowledge, pointing to the fact that "[w]e would all rather fly with a pilot who has taken off, flown, and (especially) landed in all kinds of extreme weather than with one who has always enjoyed smooth conditions" ( p. 91). Hence, an accelerated exposure to varied experiences may increase "expert insight" (Davenport \& Prusak, 2000) which builds an individual's tacit knowledge, in turn enhancing organizational knowledge retention. DeLong (2004) argues that the element of knowledge most at risk for loss due to the exit of an aging workforce is an individual's tacit or experiential knowledge. It is with these problems in mind that the authors established the theoretical framework of Replicative Indwelling with the two supporting components of Replicative SPECTRUM and Accelerated Experiential Exposure.

\section{REPLICATIVE INDWELLING}

Replicative Indwelling is a two-part 'sense-making' theoretical framework for knowledge transmission derived from Polanyi's (1962, 1966) concept of "indwelling" and Heidegger's (1996) concept of "dwelling". Replicative Indwelling is the gestalt of a functionally reconstructivist phenomenon that, as best possible, attempts to replicate the conditions which existed during the original knowledge creation process in order to maximize transmission. The authors believe that replication of knowledge creation conditions provides the shared context between individuals to facilitate knowledge transfer.

As stated by Polanyi, "[a] valid articulate framework may be a theory, or a mathematical discovery, or a symphony. Whichever it is, it will be used by dwelling in it, and this indwelling can be consciously experienced" (1962, p.208). The authors offer two systematic components of Replicative Indwelling that enable the theoretical to become practical. The first component is that of Replicative SPECTRUM. This mnemonic offers leadership a means to evaluate which organizational dimensions need to be transferred from one generation to the next. It addresses the question, "Are we indwelling on the correct dimension?" The second component enables the recreation of the mental construct through the application of the Accelerated Experiential Exposure (AEE) model. The AEE model converts "ad hoc experience into [a] system" (Drucker, 1993, p. 42) that establishes the requisite framework to communicate knowledge wholly, from within its context.

Replicative Indwelling's reconstructive approach maximizes intergenerational knowledge transfer, mitigates lost knowledge during the 'making of experts', and overcomes four of Singh and Kant's nine KM barriers. The following sections provide details on both the Replicative SPECTURM and Accelerated Experiential Exposure.

\section{The Replicative SPECTRUM}

Replicative Indwelling is possible through the Replicative SPECTRUM, which provides eight frames for organizations to address and organize the experiences shaping an individual during the phenomenon of knowledge creation. This framework recreates the mental construct in which the knowledge being transmitted was created for 
the purpose of cross-generational transmission of inter-organizational knowledge (See Figure 3 for graphic depiction). DeLong (2004) states that there are four essential types of knowledge; Human, Social, Cultural, and

Structured (pp. 22-23). A knowledge management plan that fails to address these frames is at risk to lose the knowledge that was created by its influence, placing organizational longitudinally in jeopardy.

Based upon Davenport and Prusak's (2000) operative definition of knowledge, Replicative Indwelling reconstructs the frames from which the knowledge being transmitted was created in an effort to provide holistic knowledge transmission. Providing information from these frames reconstructs the contextual-communicative dependence present during the creation of knowledge, further establishing the "'here' of my body and the 'now' of my present" (Berger \& Luckmann, 1966, p. 36).

Replicative Indwelling represents the 'here' of my body addressed by Heidegger, and the 'now' of my present, addressed by Polanyi. All knowing comes from indwelling, "[e]ven the relatively straightforward case of knowing some object arises out of the bodily, linguistic, cultural, and historical indwelling of the person (Apczynski, 2005, p. 79). By addressing the SPECTRUM frames in correspondence with the four stages of accelerated experiential exposure, organizations can not only ensure that codified knowledge is transferred for continuous utilization by the organization, but also that the tacit knowledge gained from years of experience, which gives context to the codified knowledge, is transferred as well. Each of the eight frames will now be examined in detail.

Figure 2. The Replicative SPECTRUM

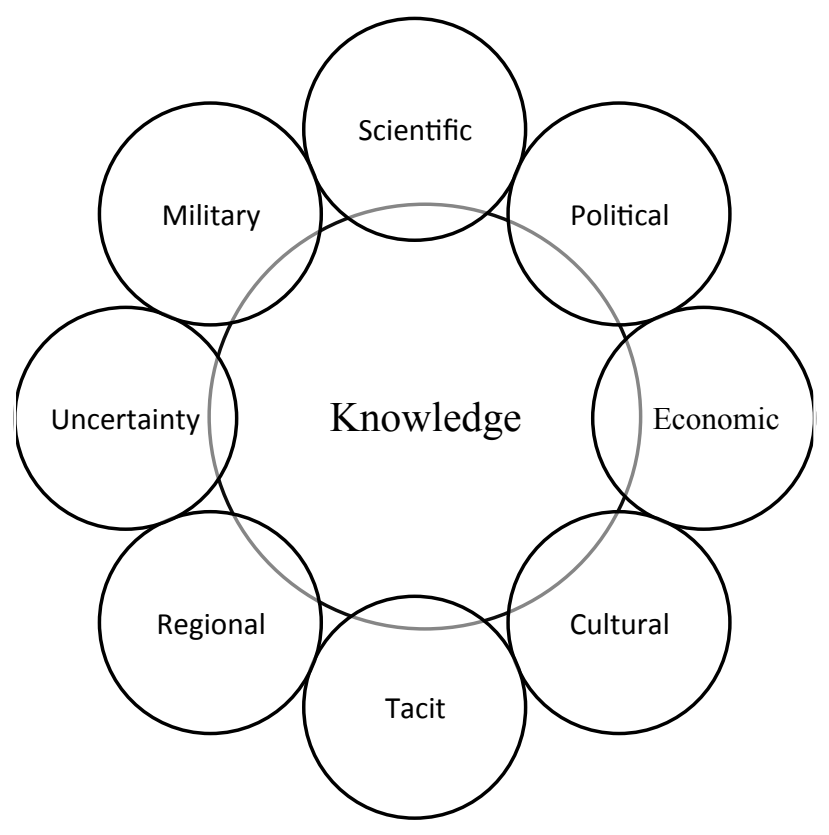

\section{Scientific}

The Scientific frame provides for the contemporary scientific paradigm, expressing boundaries, limitations, heuristics and tendencies for bias and their relationship to the creation of knowledge. It is representative of the degree of specialization of its paradigm. According to Weber (1946), "science contributes [1] ... [to] the technology of controlling life by calculating external objects as well as man's activities.... [2]...methods of thinking, [as well as] the tools and the training for thought... [3] to gain[ing] clarity [regarding the situation] (pp.150-151). It is the tendency of science to build upon what has come before, and individuals who are the recipients of organizational knowledge may not understand the concepts from which it is created. Heidegger illuminates this when he states that "[t]oday everybody is able to operate a radio or television set without knowing the laws of physics in their substantial contents... The same is valid for the task of thinking" (as cited by Porter, 2013, p. 14). 
However, knowledge is a paradigmatic product of the respective intellectual schools of thought and rules governing decision-making of the time is created and is subject to the generally accepted scientific rules and principles

governing its creation (Kuhn, 2012). Thus, in order to fully understand the knowledge being transferred, the beneficiary must have access to insights and information from the scientific paradigm in which it was created.

\section{Political}

In the information economy, knowledge workers are vital to organizational success. The output of these workers is voluntary, and they must "buy-in" to the organization, and ultimately place trust in the organizations leaders. Politics can be broadly defined as that which "comprises any kind of independent leadership in action" (Weber, 1946, p.77). There is a key relationship between leadership and effective knowledge management (Lakshman, 2007). Yet poor or weak leadership causes organizations to be faced with knowledge management barriers due to a lack of top management commitment, ownership of the problem, organizational structure, organizational culture, and a lack of motivation and reward (Singh \& Kant, 2008).

Leaders often have a difficult time fully utilizing organizational knowledge "because of misguided approaches and hurried excitement" during the implementation and development of their knowledge management program (DeTienne, Dyer, Hoopes, and Harris, 2004, p. 26). Senior organizational leaders must personally participate in knowledge management activities in order to bridge the gap between knowledge management and leadership, "giving rise to the notion of organizational knowledge leadership" (Lakshman, 2007, p. 66).

\section{Economic}

Knowledge is a commodity that has immense economic value. This fact alone should serve as an incentive for employers to make earnest efforts towards establishing favorable conditions for the creation and transfer of knowledge. However, this has not been the case in that "[e]mployees invest in the company's adaptability; the company invests in employees' employability" (Hoffman et al., 2013, p. 51). In the Information Economy, "knowledge sharing can be regarded as a business transaction process" (Barachini, 2009, p. 98). In the Information Economy, knowledge is an asset that brings value the organization in the form of competitive advantage (Mousavizadeh, Harden, Ryan, \& Windsor, 2015).

In order to fully utilize their knowledge for an economic benefit, organizations must understand that "resources, means and practices of production have become humane and reflexive in nature...Drucker maintains that value can and must be understood under the same economic conditions in the "new" knowledge-based economy as in the industrial Taylorian economy" (Bang, Cleemann, \& Bramming, 2010, p. 626). They must know the value of knowledge management and its relationship with organizational performance and longevity.

\section{Cultural}

Culture is communication and communication is culture (Hall, 1959). Yet research suggests that organizational culture was one of the largest barriers to knowledge management (De Tienne et al., 2004). Organizations must have effective methods and means of communication in order to have an effective organizational culture that is able to create, apply, and store knowledge. Organizations "become... static, rigid, [and] institutionalized when-ever... [they are] ...not employed to facilitate and enrich the contacts of human beings with one another" (Dewey, 1952, p. 207). Human beings come in 'contact' with other through communication; however, simply having effective communications will not create knowledge.

While a culture in which the value of a knowledge management program can be realized "consists of norms and practices that promote the free-flow of information among employees and across department lines" (De Tienne et al., 2004, p. 29) is essential, so too is the need to transfer the cultural knowledge of the organization. Cultural Knowledge is the knowledge that reflects how "things are done in a particular organization" (DeLong, 2004, p. 23). 


\section{Issues in Information Systems \\ Volume 17, Issue IV, pp. 70-81, 2016}

This includes not only the processes by which knowledge and information are communicated, but also to whom, and the unique context, source, or informants from which it was derived (Rogers \& Ryschkewitsch, 2009).

\section{Tacit}

During Replicative Indwelling, information must be provided in order to determine what was learned in the process of knowledge creation, as that "collateral knowledge" has tremendous organizational value as well. As previously stated, DeLong (2004) argues that the most at risk element of knowledge loss due to the exit of an aging workforce is an individual's tacit or experiential knowledge. However, "[a] personal knowledge accepted by indwelling may appear merely subjective" (Polanyi, 1962, p.215). Providing supporting context to the process of knowledge transfer "brings home to us that it is not by looking at things, but by dwelling in them, that we understand their joint meaning" (Polanyi, 1962, p.18).

Knowledge is embedded in organizational culture, routines, and practices. Providing supporting context equates to a Geertzian like thick-description in which the knowledge being transferred was created in ordered for the beneficiary to 'indwell' (1973). The information on hand at the time, documents, artifacts, the tools that were used, and these all have the potential to be conduits for the transfer of tacit knowledge. The corresponding frames of SPECTRUM can also provide context from which tacit knowledge may be transferred.

\section{Regional}

The expansion of the global economy increases the likelihood of interactions with multicultural organizations. As the geographic area in which the organization operates expands, so too does the likelihood that they encounter knowledge management issues due to cultural incongruences. Members of different cultures are apprehensive to share knowledge with one another (Wei, 2010). Research has shown that knowledge transfer within a dispersed organization is not valued in the same way that it would if it had originated locally. Katz and Allan (1982) refer to this as the "not-invented-here" syndrome (as cited by Schleimer \& Riege, 2009, p. 30).

In order to mitigate the potential for lost knowledge due to spatial proximity, organizations must incorporate a sound technological infrastructure to support the distribution of knowledge. Davenport and Prusak (2000) remind us that this technological infrastructure "does not create knowledge and cannot guarantee or even promote knowledge generation or knowledge sharing in a corporate culture that doesn't favor those activities" (p.18), affirming Carr's (2003) assertion that technological infrastructure, or IT, is a utility and can no longer be viewed as a means of obtaining or maintaining a competitive advantage; or more bluntly, "IT Doesn't Matter."

\section{Uncertainty}

The rise of the knowledge worker has given rise to the specialist. A specialist is a knowledge worker that focuses their education and careers on a narrow field of expertise. As they continue to peer deeper for knowledge, "[t]he specialist "knows" very well his own, tiny corner of the universe; he is radically ignorant of all the rest" (Gasset, 1932, p.123). Malone et al. (2011) refer to this as the "The Age of Hyperspecialization." As this specialization increases, members of an organization feel threatened by an ambiguous or unclear situation outside the scope of their narrow view of the organization.

As organizations develop, so too does the body of knowledge surrounding them, contributing to the amorphous mass of data, information, and knowledge. The danger of uncertainty in making organizational decisions can be detrimental to the organization's existence. The ability to accurately know what information is applicable, as well as the difference between data, information, and knowledge is imperative, as "[o]rganizational success and failure can often depend on knowing which of them you need, which you have, and what you can and can't do with each" (Davenport \& Prusak, 1998, p.1). 


\section{Military}

The increasing demand for information "increases the vulnerability of private and sensitive information that needs to be protected and kept confidential in organizations (Lyu \& Zhang 2015, pp. 189-190). The term Military is used as a means to visualize the need for establishing and maintaining a secure environment. The security of information is vital in the information economy, as information is now a commodity, and must be protected accordingly. Lyu and

Zhang also state that the information economy has brought together "two seemingly irrelevant fields, information security management and knowledge management" (p.191).

With the increasing value placed on knowledge and the continued growth of the Information Economy, information security is essential to the wellbeing of the organization. Manhart and Thalmann (2015) conducted an extensive analysis of knowledge protection literature and noted that more resources should be placed on tacit knowledge protection. Failing to protect knowledge can lead to the disclosure of trade secrets and could ultimately result in an organization's demise.

The results of Replicative SPECTRUM analysis offers organizational leadership insight on what information must be transferred from one generation to the next. This analysis can also assist in overcoming the knowledge transfer paradox by ensuring that critical proprietary knowledge within the organization is not transferred to those most likely to migrate quickly to another company. The next step is to actually facilitate knowledge transfer by using the Accelerated Experiential Exposure model.

\section{ACCELERATED EXPERIENTIAL EXPOSURE}

Accelerated Experiential Exposure is an inter-organizational knowledge transmission methodology that combines dilemma-based case study methods, Socratic questioning techniques, reflective practices, and action learning.

Educational institutions apply these techniques in a variety of combinations (Defense Acquisition University, n.d., 2012; DeLeon, 2012; Erskine, Leenders, \& Mauffette-Leenders, 2011; Fahim \& Bagheri, 2012; Kurfiss, 1988; Whiteley, 2006), and some of these techniques are utilized for the purpose of knowledge transmission (Asselin, Schwartz-Barcott, \& Osterman, 2013; Cox, 2005; Daudelin, 1996; Davenport \& Prusak, 2000; DeLong, 2004; Waks, 1999). However, there has been no identified method that seeks to unify all of these applications into a singular knowledge transmission process within organizations (Stahl \& Buckles, 2016).

The essence of dilemma-based case method is to place the student into the context of a situation that requires development of potential solutions, the defense of the final recommended solution to peers, and the critique of the solution by an expert who experienced the case first-hand. Constructionist Socratic questioning forces critical thinking and places the student into the original context as best possible. Action learning ensures relativity while reflection embodies the concept of "indwelling". Thus, by recreating the conditions of previous problems and requiring the student to reflect, indwelling is being replicated. Finally, by incorporating these cases on a regular professional development plan (a subset of the KM plan), exposure to experiences can be accelerated at a rate beyond that encountered during normal working conditions. (Stahl \& Buckles, 2016).

The four stage learning process used by the Defense Acquisition University is one recommended case method (see figure 2). Based on DeLeon's (2012) research, the Defense Acquisition University modified Mauffette-Leenders et al.'s (2007) three-stage learning process by adding reflection in the spirit of Schön's, The Reflective Practitioner (DeLeon, 2012; Kinsella, 2009). Reflexive learning within a supportive context will lead to an increase in critical thinking skills, potentially eliminating a number of the barriers presented by Singh and Kant (2008). 
Figure 3. Four Stage Learning Process (DAU, 2012)

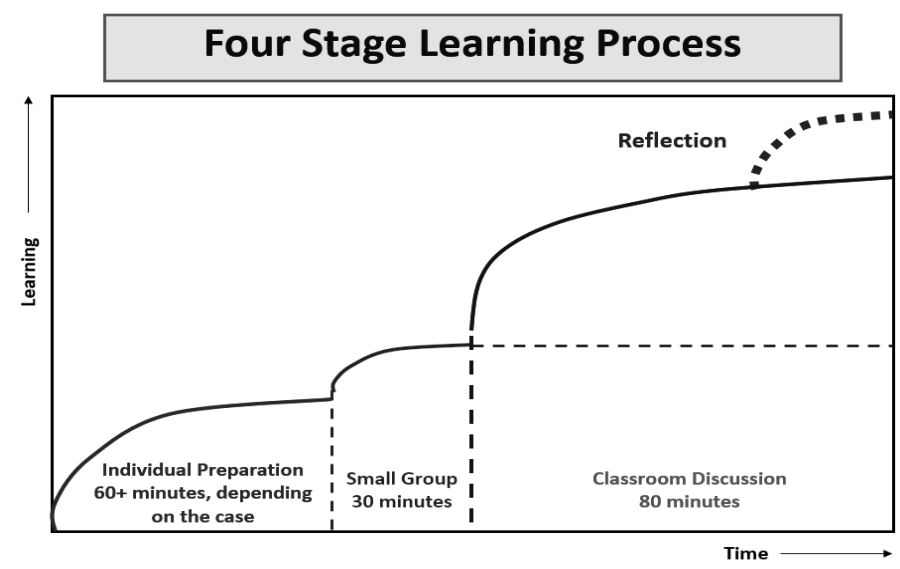

Additionally, the fourth stage of the learning process addresses Schwandt's fourth cognitive shift in adult learners. Specifically, Schwandt (2005) states that for adult learners, "individual (and collective) reflection has shifted from a simple response to stimuli, or a step in the problem-solving process, to the fundamental introspective process required for change to occur in basic assumptions, premises, and sensemaking frameworks" (p. 181).

Reflection takes on two primary roles in order to aid in the mitigation of lost knowledge. Reflection serves as a means to take newly acquired knowledge, process it, and then absorb it in the manner described by Davenport and Prusak (2000). The absorption of knowledge is the heart of knowledge transfer. The tacit knowledge of the senior workforce member becomes evident and explicit during the large group discussion. That knowledge is then critically examined during the critique phase of the discussion, and then absorbed at a deeper level during the reflection process. Davenport and Prusak (2000) insist “[k]nowledge that isn't absorbed hasn't really been transferred" (p. 181).

\section{CONCLUSION}

The retention and utilization of organizational knowledge should be the goal for all knowledge management plans. Experts are not born, they are made. There are no shortcuts to take while becoming an expert. In fact, "[i]t will take you at least a decade to achieve expertise, and you will need to invest that time wisely, by engaging in 'deliberate' practice - practice that focuses on tasks beyond your current level of competence and comfort" (Ericsson, Prietula, \& Cokely, 2007, p. 116). Tacit knowledge gained from experience is one of the most important drivers of innovation and change (Testa as cited by Liebowitz \& Simon, 2007). By applying the principles of Replicative Indwelling, the tacit knowledge of a senior workforce member becomes explicit and is able to be transferred. Organizationally, "[t]acit knowledge is often learned via shared and collaborative experiences. Both trust and mutual understanding, developed in their social and cultural contexts, are prereqs for successful transfer of tacit knowledge" (Liebowitz et al., 2007, p. 1136). Replicative Indwelling combines sociological, organizational, educational, and philosophical research to ensure that DeLong's (2004) four essential types of knowledge are transferred, as well as to ensure the presence of shared experiences, trust, and understanding within a given context. Additionally, the application of the Replicative Indwelling concepts can mitigate issues of the knowledge transfer paradox within the Information Age, and can aid in overcoming key knowledge management barriers by providing a KM methodology, increasing organizational structure, codifying organizational culture, and accounting for staff retirement.

\section{REFERENCES}

Albers, J. A. (2009). A practical approach to implementing knowledge management. Journal of Knowledge Management Practice, 10(1). 
Andersson, C. (2008). Sophisticated selectionism as a general theory of knowledge. Biology \& Philosophy, 23, 2, 229-242.

Apczynski, J. V. (2005). The discovery of meaning through scientific and religious forms of indwelling. Zygon: Journal Of Religion \& Science, 40(1), 77. doi:10.1111/j.1467-9744.2005.00645

Asselin, M. E., Schwartz-Barcott, D., \& Osterman, P. A. (2013). Exploring reflection as a process embedded in experienced nurses' practice: A qualitative study. Journal of Advanced Nursing, 69(4), 905-914.

Bang, A., Cleemann, C. M., \& Bramming, P. (2010). How to create business value in the knowledge economy. Management Decision, 48(4), 616-627.

Barachini, F. (2009). Cultural and social issues for knowledge sharing. Journal of Knowledge Management, 13(1), 98-110.

Berger, P. L., \& Luckman, T. (1966). The social construction of reality: A treatise in the sociology of knowledge. Garden City, NY: Anchor Books.

Bolman, L. G. \& Deal, T. E. (2013). Reframing organizations: Artistry, choice, \& leadership (5 $5^{\text {th }}$ ed.). San Francisco, CA: Wiley \& Sons.

Carr, N. G. (2003). IT doesn't matter. Harvard Business Review, 81(5), 41-49.

Cox, E. (2005). Adult learners learning from experience: Using a reflective practice model to support work-based learning. Reflective Practice, 6(4), 459-472.

Cranefield, J., Pak, Y., \& Huff, S. L. (2015). Rethinking lurking: Invisible leading and following in a knowledge transfer ecosystem. Journal of the Association for Information Systems, 16(4), 213-247.

Daudelin, M. W. (1996). Learning from experience through reflection. Organizational Dynamics, 24(3), 36-48.

Davenport, T. H., \& Prusak, L. (2000). Working knowledge: How organizations manage what they know. Boston, MA: Harvard Business School Press.

Defense Acquisition University (n.d.). Reading for discussion of reflection-FPD-18 frameworks for reflection. Course material, Faculty Professional Development Course 18. Defense Acquisition University, Ft. Belvoir, VA.

Defense Acquisition University (2012). Course material. Case Teaching Workshop (FPD-151), Faculty Professional Development, 4-7 December 2012. Defense Acquisition University, Ft. Belvoir, VA.

DeLeon, B. G. (2012). Exploration of action learning and critical thinking: A study of the critical thinking development of senior managers (Doctoral Dissertation). Available from ProQuest Dissertations \& Theses Global. (992880112). (Order No. 3502746)

DeLong, D. W. (2004). Lost knowledge: Confronting the threat of an aging workforce. Oxford: Oxford University Press.

DeTienne, K. B., Dyer, G., Hoopes, C., \& Harris, S. (2004). Toward a model of effective knowledge management and directions for future research: Culture, leadership, and CKOs. Journal Of Leadership \& Organizational Studies, 10(4), 26-43.

Drucker, P. F. (1993). Post-capitalist society. New York, NY: Harper Business. 
Drucker, P. F. (1999). Knowledge-worker productivity: The biggest challenge. California Management Review, 41(2), 79-94. doi: 10.2307/41165987

Drucker, P. F. (2000). The change leader. Tooling \& Production, 66(1), 78.

Ericsson, K. A., Prietula, M. J., \& Cokely, E. T. (2007). The making of an expert. Harvard Business Review, $85(7 / 8), 114-121$.

Erskine, J. A., Leenders, M. R., \& Mauffette-Leenders, L. A. (2011). Teaching with cases ( $^{\text {rd }}$ ed.). London, ONT: Ivey Publishing.

Fahim, M., \& Bagheri, M. B. (2012). Fostering critical thinking through Socrates' questioning in Iranian language institutes. Journal of Language Teaching and Research, 3(6), 1122-1127.

Fuchs, M. (2014). Worldwide knowledge? Global firms, local labour and the region. Farnham: Routledge.

Garcia, A., Standlee, A., Bechkoff, J., \& Cui, Y. (2009). Ethnographic Approaches to the Internet and ComputerMediated Communication. Journal of Contemporary Ethnography, 38(1), 52-84.

Gasset, O. J. (1932). The revolt of the masses: Authorized translation from the Spanish. New York, NY: W.W. Norton \& Co.

Heidegger, M., \& Stambaugh, J. (1996). Being and time: A translation of Sein und Zeit. Albany, NY: State University of New York Press.

Kennedy, E. U. (2014). Knowledge management and global information dissemination. Education, 134(3), 395-403.

Kidd, J. (2004). Leading with knowledge: Knowledge management practices in global infotech companies. Knowledge Management Research \& Practice, 2(2), 133-134.

King, W. R. (Ed.). (2009). Knowledge management and organizational learning. Annals of Information Systems, 4, 3-13. Springer Science Business Media, LLC. doi 10.1007/978-1-4419-0011-1_1

Kurfiss, J. G. (1988). Critical thinking: Theory, research, practice, and possibilities. ASHE-ERIC Higher Education Report No.2. Association for the Study of Higher Education. Washington, D.C.: ERIC Clearinghouse on Higher Education.

Lakshman, C. (2007). Organizational knowledge leadership: A grounded theory approach. Leadership \& Organization Development Journal, 28(1), 51-75.

Leonard, D., \& Swap, W. (2004). Deep smarts. Harvard Business Review, 82(9), 88-97.

Liebowitz, J. (1999). Key ingredients to the success of an organization's knowledge management strategy. Knowledge and Process Management, 6(1), 37-40.

Liebowitz, J., Ayyavoo, N., Nguyen, H., Carran, D., \& Simien, J. (2007). Cross-generational knowledge flows in edge organizations. Industrial Management \& Data Systems, 107(8), 1123.

Lyu, H., \& Zhang, Z. (2015). Job Quitters, Information Security Awareness, and Knowledge Management Strategies. Journal of Information Privacy \& Security, 11(4), 189. doi:10.1080/15536548.2015.1105594 
Malone, T. W., Laubacher, R. J., \& Johns, T. (2011). The big idea: The age of hyperspecialization. Harvard Business Review, 89, 7-8.

Mayer, P. S. (2000). The Human Side of Knowledge Management: An Annotated Bibliography (No. 349). Greensboro, NC: Center for Creative Leadership.

Mousavizadeh, M., Harden, G., Ryan, S., \& Windsor, J. (2015). Knowledge management and the creation of business value. The Journal of Computer Information Systems, 55(4), 35-45.

Nag, R., \& Gioia, D. A. (2012). From Common to Uncommon Knowledge: Foundations of Firm-Specific Use of Knowledge as a Resource. Academy Of Management Journal, 55(2), 421-457.

Nonaka, I., \& Takeuchi, H. (1995). The knowledge-creating company: How Japanese companies create the dynamics of innovation. New York, NY: Oxford University Press.

Polanyi, M. (1962). Personal knowledge: Towards a post-critical philosophy. London: Routledge.

Polanyi, M. (1966). The tacit dimension. Garden City, N.Y: Doubleday.

Rogers, E., \&, M. Ryschkewitsch (2009). Knowledge reapplication: Enhancing organization learning at NASA. $A$ Discussion Paper. NASA HQ. Washington, DC.

Schleimer, S., \& Riege, A. (2009). Knowledge transfer between globally dispersed units at BMW. Journal of Knowledge Management, 13(1), 27-41.

Schwandt, D. R. (2005). When managers become philosophers: Integrating learning with sensemaking. Academy $O f$ Management Learning \& Education, 4(2), 176-192.

Singh, M. D., \& Kant, R. (2008). Knowledge management barriers: An interpretive structural modeling approach. International Journal of Management Science and Engineering Management, 3, 2, 141-150.

Stahl, B., \& Buckles, B. (2016). Replicative indwelling: Mitigating lost knowledge through accelerated experiential exposure. Online Journal of Applied Knowledge Management, 4(2), 110-127.

Stovel, M., \& Bontis, N. (2002). Voluntary turnover: knowledge management - friend or foe? Journal of Intellectual Capital, 3(3), 303-322. doi 10.1108/14691930210435633

Tseng, M. (2010). An assessment of cause and effect decision-making model for firm environmental knowledge management capacities in uncertainty. Environmental Monitoring and Assessment, 161(1-4), 549-564.

Waks, L. J. (1999). Reflective practice in the design studio and teacher education. Journal of Curriculum Studies, 31(3), 303-316.

Weber, M., \& Mills, C. W. (1946). From Max Weber: Essays in Sociology. Translated, Edited, and with an Introduction. by H.H. Gerth and C. Wright Mills. H. Gerth (Ed.). New York, NY: Oxford University Press [1973].

Wei, L. (2010). Virtual knowledge sharing in a cross-cultural context. Journal of Knowledge Management, 14(1), $38-50$.

Whiteley, T. R. (2006). Using the Socratic method and Bloom's taxonomy of the cognitive domain to enhance online discussion, critical thinking, and student learning. Developments in Business Simulation and Experiential Learning, 33, 65-70. 